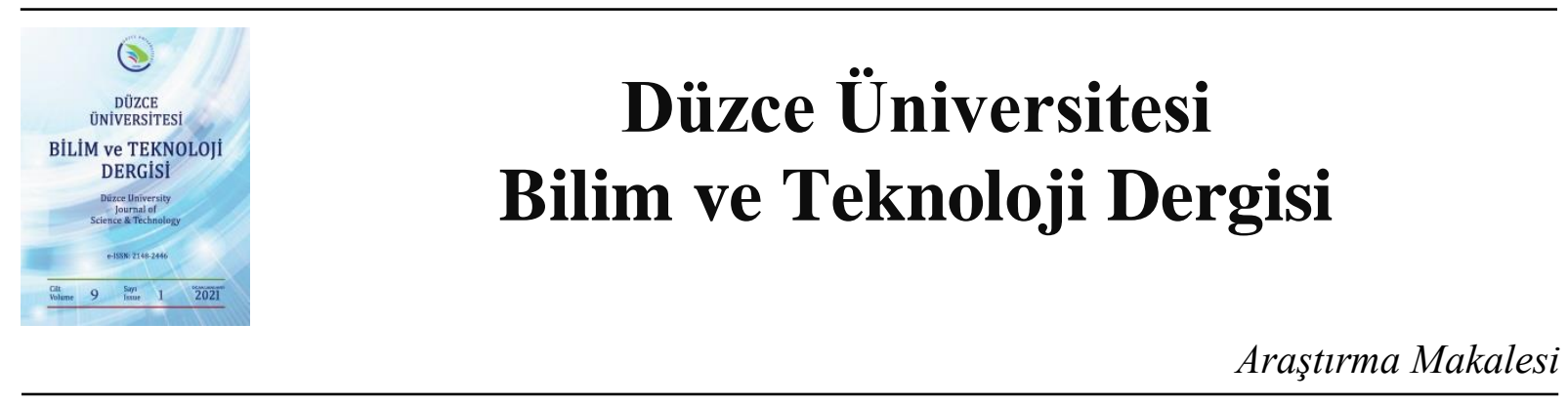

\title{
Genleştirilmiş Cam Küre Agrega Katkılı Harçların Bazı Özelliklerinin İncelenmesi
}

\author{
D Burak AKTÜRK ${ }^{a}$, (D) Mustafa DAYI ${ }^{b^{*}}$, (D) H.Ylmaz ARUNTAŞ ${ }^{c}$ \\ ${ }^{a} Y$.Müh., Aktürk Mühendislik, Düzce/Türkiye \\ ${ }^{b}$ Düzce Üniversitesi, İnşaat Mühendisliği Bölümü, Mühendislik Fakültesi, Düzce/Türkiye \\ ${ }^{c}$ Gazi Üniversitesi, İnşaat Mühendisliği Bölümü, Teknoloji Fakültesi, Ankara/Türkiye \\ "Sorumlu Yazar: mustafadayi@duzce.edu.tr
}

DOI : 10.29130/dubited.729582

\begin{abstract}
ÖZET
Bu çalışmada atık camdan üretilmiş olan genleştirilmiş cam küre (GCK) ikame edilmiş harçların mekanik ve fiziksel performansları araştırılmıştır. Bu amaçla agrega olarak, genleştirilmiş cam küre agregası ve doğal kum ile bağlayıcı olarak çimento ve kirecin kullanıldığı harç karışımları hazırlanmıştır. Karışımlarda 1-2 mm ve 2-4 mm boyutlarında genleştirilmiş cam küre aynı boyutlardaki kum ile hacimce $\% 0, \% 25, \% 50$ ve $\% 100$ oranlarında yer değiştirilerek kullanılmıştır. Harç karışımları 40×40×160 mm ebatlı kalıplara dökülmüş ardından 7, 28 ve 56 günlük kür sürelerine tabi tutulmuştur. Kür sonunda harç serilerinde sertleşmiş birim hacim ağırlık, porozite, kütlece su emme, ultrasonik geçiş hızı ile basınç dayanımı deneyleri yapılmıştır. Sonuç olarak; atık bir madde olan camın geri dönüştürülmesiyle oluşan genleştirilmiş cam kürenin harç içine katılmasıyla kazanılan performanslar neticesinde geleneksel harçlarda kullanılabileceği belirlenmiştir.
\end{abstract}

Anahtar Kelimeler: Agrega, Genleştirilmiş cam küre, Harç

\section{Examination of Some Properties of Mortar with Expanded Glass Sphere Aggregate}

\begin{abstract}
In this study, mechanical and physical performance of expanded glass sphere (EGS) substitute mortars produced from waste glass were investigated. For this purpose, aggregate, expanded glass sphere aggregate and natural sand and cement and lime mortar mixtures were used as binders. In the mixtures, 1-2 $\mathrm{mm}$ and 2-4 mm expanded glass spheres were used with sand of the same dimensions by replacing $25 \%, 50 \%$ and $100 \%$ by volume. Mortar mixtures have been poured into moulded $40 \times 40 \times 160 \mathrm{~mm}$ sizes and are subjected to daily curing times of 7,28 and 56. At the end of curing, hardened unit volume weight, porosity, water absorption, ultrasonic speed and bending tensile strength tests were performed in mortar series. As a result; It is determined that the expanded glass sphere formed by recycling of waste glass can be used in traditional mortars.
\end{abstract}

Keywords: Aggregate, Expanded glass sphere, Mortar.

Geliș: 29/04/2020, Düzeltme: 20/10/2020, Kabul: 17/11/2020 


\section{GIRIS}

Agregalar, doğal ve yapay olarak farklı özelliklere sahip taşlardan, seramiklerden, metallerden, organik maddelerden elde edilen yapı malzemeleridir. Malzemeden istenilen performansa göre farklı granülometrik oranlarda karışım içerisinde kullanılmaktadırlar. Kompozit malzeme bileşeni olarak, taneli malzemenin en yaygın kullanıldığı alan beton ve harç teknolojileridir. Harç içerisinde kullanılan agrega-kum $\left(\mathrm{d}_{\max }<4 \mathrm{~mm}\right)$ oranı, betonu oluşturan agreganın hacimce oranı ile aynı olup tüm hacmin yaklaşı $\% 75$ 'ini meydana getirmektedir [1].

Harç, doğal veya yapay ince agrega ile bağlayıcı malzemenin (çimento, kireç vb.) yeteri miktarda su ile harmanlanması sonucu meydana gelen kompozit bir malzemedir. Harç, bağlayıcının su ile birleşiminde meydana gelen kimyasal reaksiyon sonucu katılaşarak sertleşmektedir. Yap1 elemanlarının yüzeyinde sıva veya dolgu malzemesi olarak ve kargir yapı elemanlarının birleştirilmesinde kenetleyici olarak rol alan bir yapı malzemesidir.

Dünya üzerinde hafif agreganın kullanımı Babil'in inşasına kadar uzanmaktadır. Antik Yunan ve Roma'da gözenekli bir malzeme olan Bims (Pomza), hem hafif agrega olarak hem de ögütülerek hidrolik bağlayıcıya katılmış; amfi tiyatro, tapınak, su kemeri gibi farklı yapıların inşasında yaygın olarak kullanılmıştır. Günümüzde en yaygın kullanılan hafif agregalar, doğal malzemelerin firınlarda yüksek sıcaklıkta genleştirilmesi ile üretilen yapay hafif agregalar olup; ilk üretim çalışmaları 1900'lerde başlamış, ilk ticari kullanımları ise I. Dünya Savaşı sırasında, çelik kıtlığı nedeniyle, "ferrocement" ticari gemilerin üretimi ile ortaya çıkmıştır [2].

Yapı teknolojisinde statik ve dinamik açıdan yapıda hafifliğin sağlanmasının yanı sıra yapıya bu hafifliği sağlayacak olan yapı elemanlarının da olabildiğince hafif ve standartlara uygun özellik gösteren malzemelerden seçilmeleri son derece önem arz etmektedir.

Hafif agregalar beton ve harç içerisinde kullanılarak inşaattaki sabit yükler azaltılır, etkiyecek deprem kuvveti indirgenmiş olur dolayısı ile taşıyıcı elemanların kesitleri küçülür ve maliyette ciddi oranda azalmalar meydana gelir.

Günümüzde sıva, harç, tuğla, taşıyıcı ve taşıyıcı olmayan yapı blokları ve beton içerisinde hafif agrega kullanılarak hafif modern yapı malzemeleri üretilmektedir. Yapı malzemelerinin hafifliğinin yanı sıra teknolojik özelliklerinin de geliştirilmesi bir gereklilik haline gelmiştir. Konutlarda kullanılan enerji miktarının önemli bir bölümü bina 1sıtılmasında tüketilmektedir. Enerjide dışa bağımlılık ve hava kalitesinin gün geçtikçe azalıyor olması 1sı yalıtımı için alınacak tedbirlerin gerekliliğini göz önüne sermektedir.

Yapılan çalışmalarda hafif ağırlıklı agregaların gözenekleri sayesinde bu malzeme ile üretilmiş betonun daha yüksek dayanım/ağırlık oranına, daha az yarmada çekme dayanımı kapasitesine, düşük 1sıl genleşme değerine, yüksek nitelikli 1sı ve ses yalıtımı özelliklerine sahip olduğunu rapor edilmiştir. Buna ek olarak betonda hafif ağırlıklı agrega kullanılmasıyla yapının zati ağırlığının ve kullanılacak demir donatı miktarının azalacağı ortaya koyulmuştur [3-6].

Genleştirilmiş cam, genleştirilmiş kil ve köpük camdan oluşan üç farklı tipte genleştirilmiş agrega kullanılarak hafif betonların üretildiği bir çalışmada, fiziksel, bilgisayarlı tomografiyle mikro yapı ve mekanik özellikler araştırılmıştır. Üretilen hafif betonların normal betona göre daha düşük termal 
iletkenlik gösterdiği ayrıca referans normal agregalı numuneye göre çok daha düşük su emme özelliği gösterdiklerini tespit etmişlerdir [7].

Subaş1 vd. yapmış olduğu çalışmasında beton içerisinde farklı oranlarda genleştirilmiş kil agregası kullanarak $1,7 \mathrm{~kg} / \mathrm{m}^{3}$ gibi düşük bir yoğunlukta ve basınç dayanımı 41,27 MPa olan taşı1ııı hafif beton elde etmenin mümkün olduğunu belirlemiştir. Üretimi gerçekleştirilen hafif beton karışımlarında 450'lik bir dozaja sahip betonların en yüksek basınç ve yarmada çekme dayanımı değerlerine sahip olduğunu tespit etmiştir [8].

Yapılan başka bir çalışmada ince agrega yerine \%25 genleştirilmiş perlit agregası (GPA) kullanıldığında 1sı iletkenlik katsayısının azaldığını, ayrıca \%10, \%20 cam tozu (CT) içeren 28 günlük harç numunelerinin isı iletkenlik değerlerinde sırasıyla \%1, \%4 azalma olduğu belirlenmiştir. Bununla birlikte \%25 GPA'lı ve mineral katkıların bütün seviyelerinde harçların 1sı iletkenlik, basınç dayanımı, eğilme dayanımı ve kuru birim ağırlık değerlerinde azalma olduğu belirlenmiştir [9].

Aytekin çalışmasında çimento harç numunelerinde sepiyolit ikamesinin artmasıyla, numunelerin su emme miktarlarının arttığı, bulk ve doygun kuru yüzey yoğunluklarının azaldığı ve gözeneğin arttığı belirlemiştir. Harç numunelerinin mekanik özellikleri incelendiğinde ise, eğilme ve basınç dayanımlarında en yüksek değerleri referans numunesi verirken, en düşük değerleri \%15 sepiyolit ikameli numunenin verdiğini tespit etmiştir [10].

Gadea ve arkadaşlarının yaptığı bir çalışmada poliüretan atıklarının harç içerisinde kullanarak hafif agregalı harç elde etmişlerdir. Harç içerisindeki poliüretan miktarının artmasıyla, işlenebilirlik, geçirgenlik ve porozitenin arttığını, yoğunluk ve mekanik özelliklerin azaldığını tespit etmişlerdir. [11].

Bu çalışmada, cam atıklarından üretilen genleştirilmiş cam küre agregasının (GCK) harç içinde doğal agregaya ikame edilerek farklı bağlayıcılarla kullanılabilirliği incelenmiştir. Bu bağlamda çimento ve kireç bağlayıcıları ile doğal kum agregasının iki fraksiyonuna farklı oranlarda GCK ikame edilmesiyle elde edilen harçların fiziksel ve mekanik özellikleri araştırılmıştır.

\section{MATERYAL VE METOT}

Çalışmada doğal ve yapay olmak üzere iki tip agrega kullanılmıştır. Kullanılan doğal kum agregası, Sakarya il sınırlarında bulunan kil miktarı oldukça az olan bir ocaktan temin edilmiştir. Çalışmada kullanılan kuma ait granülometri eğrisi Şekil 1'de verilmiştir. 


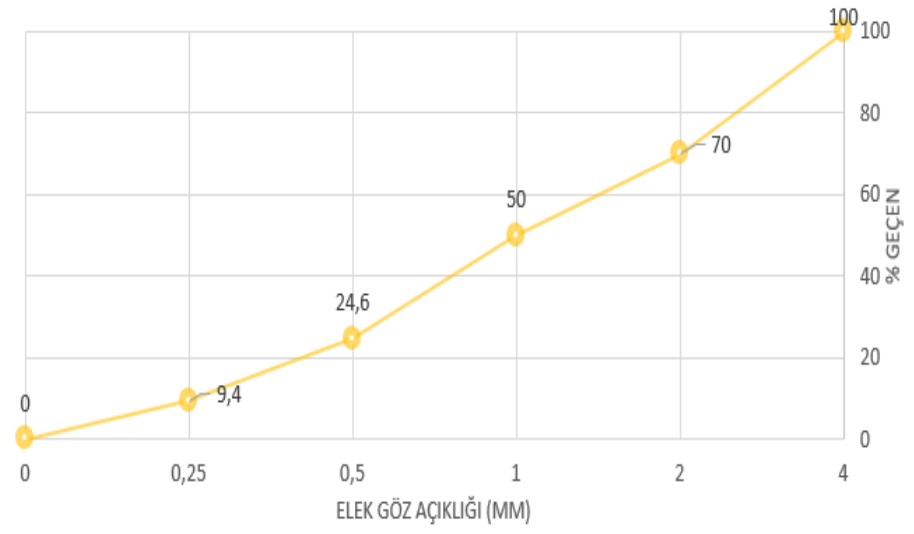

Şekil 1. Doğal agregaya ait granülometri ĕgrisi

GCK agregası Stikloporas firmasının Litvanya fabrikasında üretilmiş ve ülkemizdeki distribütörü olan Omnis Kompozit Ltd. firmasından karışıma uygun aralıklarda hazır olarak temin edilmiştir. GCK agregasına ait SEM ve makro görüntüler Şekil 2'de verilmiştir.

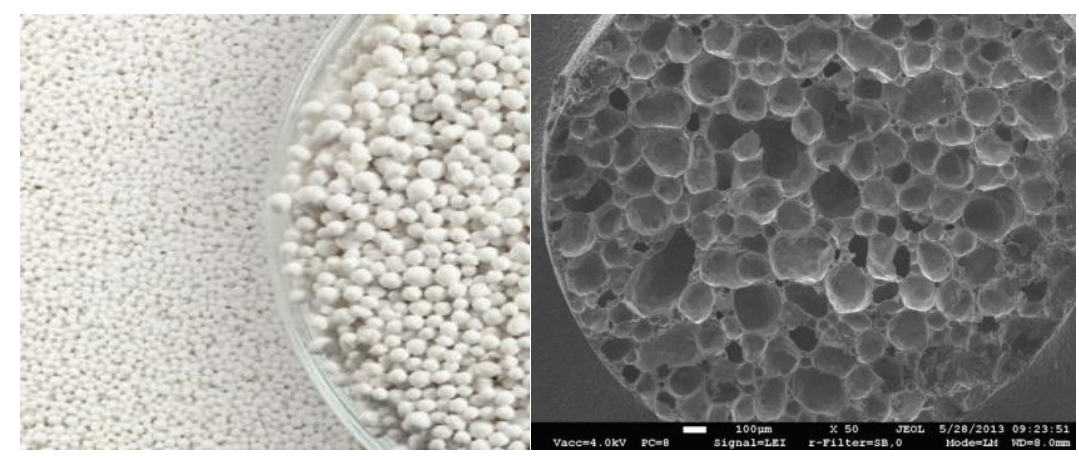

Şekil 2. GCK agregasina ait makro ve SEM görüntüsü [12]

Geri dönüşümle kazanılan hurda camın, özel patentli teknoloji ile küçük hücresel bir yapıya dönüştürülmesi sonucu elde edilen genleştirilmiş cam kürecikler, özel bir termal izolasyon malzemesi görevi yapmaktadır. Bu özelliği, Şekil 2'de görülmekte olan SEM görüntüsünde farklı çapta boşluklara sahip kapalı hücre yapısı ile sağlamaktadır. Alev direncine sahip Al sınıfı yanmazlık özelliğinde olup, tamamen su içerisine batırılsa bile gözenekli yapısı sayesinde \%10'dan fazla emilimi engellemektedir. Her türlü organik ve inorganik kimyasala karşı tamamen dirençli bir yapıda olan kürecikler ekolojik, çevre dostu bir üründür. Hafif agrega olması nedeniyle hafif beton ve harç üretiminde kullanılabilecek ideal bir malzemedir [12]. Çalışmada kullanılan GCK agregasına ait teknik özellikler Tablo 2'de verilmiştir [13].

Deneysel çalışmada bağlayıcı olarak Oyak Çimento üretimi TS EN 197-1 standartlarına uygun CEM IV/B (P) 32,5 R-Puzolanik (Doğal) Çimento ile Paksan-Adapazarı firmasının TS EN 459-1 standartlarında ürettiği CL80S sönmüş kalsiyum toz kireci kullanılmış olup ilgili firmalardan alınan kimyasal ve fiziksel özellikler Tablo 1'de verilmiştir. Karışım suyu olarak Düzce şehir şebeke suyu kullanılmıştır. 
Tablo 1. Puzolanik çimento ve kirece ait özellikler

\begin{tabular}{|c|c|c|}
\hline Özellikler & $\begin{array}{c}\text { CEM } \\
\text { IV/B(P) }\end{array}$ & $\begin{array}{l}\text { CL80 } \\
\text { S }\end{array}$ \\
\hline $\mathrm{Ca}(\mathrm{OH})_{2}$ & & 85 \\
\hline $\mathrm{CaO}$ & 46.11 & \\
\hline $\mathrm{SiO}_{2}$ & 29.85 & 1.29 \\
\hline $\mathrm{Al}_{2} \mathrm{O}_{3}$ & 7.37 & 0.26 \\
\hline $\mathrm{Fe}_{2} \mathrm{O}_{3}$ & 4.18 & 0.49 \\
\hline MgO & 2.04 & 3.25 \\
\hline $\mathrm{Na}_{2} \mathrm{O}$ & 1.31 & \\
\hline $\mathbf{K}_{2} \mathbf{O}$ & 1.96 & \\
\hline $\mathrm{SO}_{3}$ & 1.75 & 0.65 \\
\hline Kızdırma Kaybı & 3.85 & \\
\hline $\begin{array}{l}\text { 7. gün basınç d. } \\
\text { (MPa) }\end{array}$ & 22.9 & \\
\hline $\begin{array}{l}\text { 28. gün basınç d. } \\
\text { (MPa) }\end{array}$ & 35.2 & \\
\hline $\begin{array}{l}\text { Özgül yüzey } \\
\left(\mathrm{cm}^{2} / \mathrm{g}\right)\end{array}$ & 3950 & \\
\hline $\begin{array}{l}\text { Özgül ağırlık } \\
\left(\mathrm{g} / \mathrm{cm}^{3}\right)\end{array}$ & 2.94 & \\
\hline
\end{tabular}

Tablo 2. GCK'nın teknik özellikleri [13]

\begin{tabular}{l|c}
\multicolumn{1}{c|}{ Özellikler } & GCK(4-8 mm) \\
\hline $\begin{array}{l}\text { Birim hacim } \\
\text { ağırlık (g/cm })\end{array}$ & 0.20 \\
\hline $\begin{array}{l}\text { Basınç dayanımı } \\
\text { (MPa) }\end{array}$ & 1.2 \\
\hline $\begin{array}{l}\text { Termal iletkenlik } \\
\text { (W/mK) }\end{array}$ & 0.0631 \\
\hline Kütlece su emme (\%) & 20 \\
\hline
\end{tabular}

\section{A. YÖNTEM}

Harç karışımlarına GCK ikame edilerek bağlayıcı çeşitliliğine göre iki farklı grup oluşturulmuştur. Bağlayıcı olarak ilk karışım sadece çimentodan oluşmakta, ikinci karışım ise ağırlıkça $2 / 3$ oranında çimento ve $1 / 3$ oranında kireç kullanılarak tasarlanmıştır. Her iki grup karışımda, $1-2 \mathrm{~mm}$ ve $2-4 \mathrm{~mm}$ aras1 kum hacimsel olarak $\% 0, \% 25, \% 50$ ve $\% 100$ oranlarında GCK ile yer değiştirilerek kullanılmıştır. Her bir grup için referans seriler dahil dört seri olmak üzere toplamda sekiz seri harç ve 72 adet prizma harç numunesi üretilmiştir. Harç numunelerinin üretiminde bağlayıcı tipine göre isimlendirmeler yapılmıştır. Bağlayıcı olarak sadece çimento kullanılan numuneler "Ç", kireç ve çimentonun birlikte kullanıldığı numuneler "KÇ” olarak kodlanmıştır. 


\begin{tabular}{ll}
$\begin{array}{l}\text { Numune } \\
\text { Adı }\end{array}$ & İçeriği \\
\hline ŞÇ & Ç + D \\
\hline Ç25 & Ç + \%75 D + \%25 GCK \\
\hline Ç50 & Ç + \%50 D + \%50 GCK \\
\hline Ç100 & Ç + \%0 D \%100 GCK \\
\hline ŞKÇ & $\mathrm{K}+\mathrm{C}+\mathrm{D}$ \\
\hline KÇ25 & $\mathrm{K}+\mathrm{C}+\% 75 \mathrm{D}+\% 25 \mathrm{GCK}$ \\
\hline KÇ50 & $\mathrm{K}+\mathrm{Ç}+\% 50 \mathrm{D}+\% 50 \mathrm{GCK}$ \\
\hline KÇ100 & $\mathrm{K}+$ Ç + \%0 D \%100 GCK \\
\hline Not: D:Doğal agrega, Ç: Çimento, K: Kireç, GCK: Genleștirilmiş cam küre)
\end{tabular}

Harç numuneleri $40 \times 40 \times 160 \mathrm{~mm}$ ebatlarında üçlü çelik kalıplara yerleştirilmiş ve kalıpta bir gün bekletildikten sonra kalıptan çıkarılarak deney gününe kadar suda kürlenmiştir. Kür uygulanan numuneler üzerinde 7 gün, 28 gün ve 56 gün yaşlarında basınç dayanımı deneyleri ile 28 gün yaşlarında birim hacim ağırlık, porozite, kütlece su emme deneyi ve ultrasonik geçiş hızı deneyleri gerçekleştirilmiştir.

\section{III.BULGULAR VE TARTIȘMA}

Genleştirilmiş cam kürenin hafif agrega olarak kullanıldığı ve farklı iki bağlayıcı ile üretilen harçların fiziksel ve mekanik özelliklerinin araştırılması üzerine yapılmış olan bu çalışmada elde edilen sonuçlar aşağıda verilmiştir.

\section{A. FIZIKSEL ÖZELLIKLER}

Birim hacim ağırlık deneyleri 28 günlük prizma harç numuneleri üzerinde yapılmış ve elde edilen değerler Şekil 3'de verilmiştir. Veriler incelendiğinde, en düşük birim ağırlığın $1.31 \mathrm{~g} / \mathrm{cm}^{3}$ ve en yüksek değerin ise $1.94 \mathrm{~g} / \mathrm{cm}^{3}$ olarak sırasıyla KÇ100 ve ŞÇ serilerinde olduğu tespit edilmiştir. KÇ grubu harç serilerinde birim ağırlığın Ç serilerine göre ortalama \%4 oranında daha az olduğu belirlenmiştir. Harç içerisinde GCK oranının artışıla serilerin belirgin bir şekilde birim hacim ağırlıklarının azaldığı tespit edilmiştir. Ç grubunda \%100 GCK agregalı serilerin referans seriden $\% 27$ daha düşük sonuç verdiği aynı şekilde KÇ grubunda ise aynı serilerin bu değeri \%31 oranında olduğu tespit edilmiştir. 


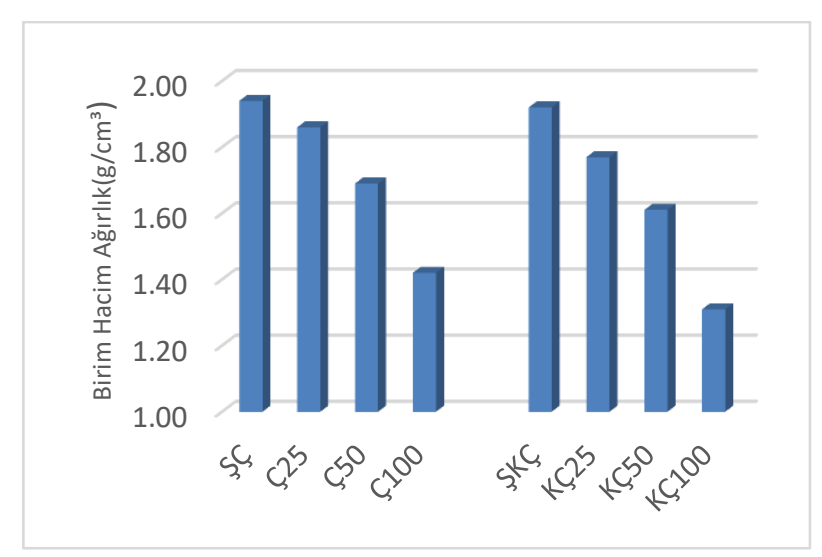

Şekil 3. Harç serilerine ait birim hacim ă̆ırlık dĕgerleri

Numunelerin boşluk hacminin toplam hacmine bölünmesiyle elde edilen porozite değerleri Şekil 4'te gösterilmiştir. Ç grubu harçlarda porozite oranlarının \%18.5 ile \%37 arasında, KÇ grubu harçlarda porozite oranlarının \%19 ile \%42 arasında olduğu hesaplanmışır. Grafik incelendiğinde çimento ve kireç bağlayıcılı serilerin porozite değeri sadece çimento bağlayıcısı kullanılan serilere nazaran daha yüksek çıktığı belirlenmiştir. Bu durum kirecin çimentoya göre daha gözenekli bir yapıya sahip olması ile açıklanabilir.

Şekil incelendiğinde, GCK'nın makro görüntülerinden elde edilen \%60-70 makro ve mikro boşluk oranına sahip GCK miktarının harç içinde kullanımının artmasıyla, serilerdeki porozite değerinin arttı̆̆ hesaplanmıştır. Yapılan benzer çalışmalarda da porozite oranlarının doğal veya yapay hafif agrega kullanımıyla arttığı görülebilmektedir [3, 6, 7].

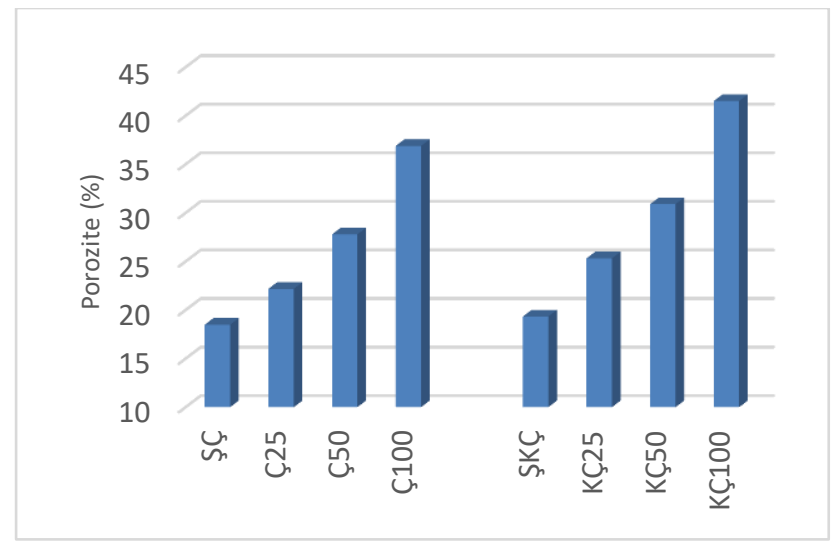

Şekil 4. Harç serilerine ait porozite değerleri

28 günlük numuneler üzerinde yapılan su emme deneyinin verileri Şekil 5'te gösterilmiştir. İlgili şekil incelendiğinde harç içerisinde GCK miktarının artmasıyla doğru orantılı bir şekilde kütlece su emme oranının da belirgin bir şekilde arttığı görülmüştür. 


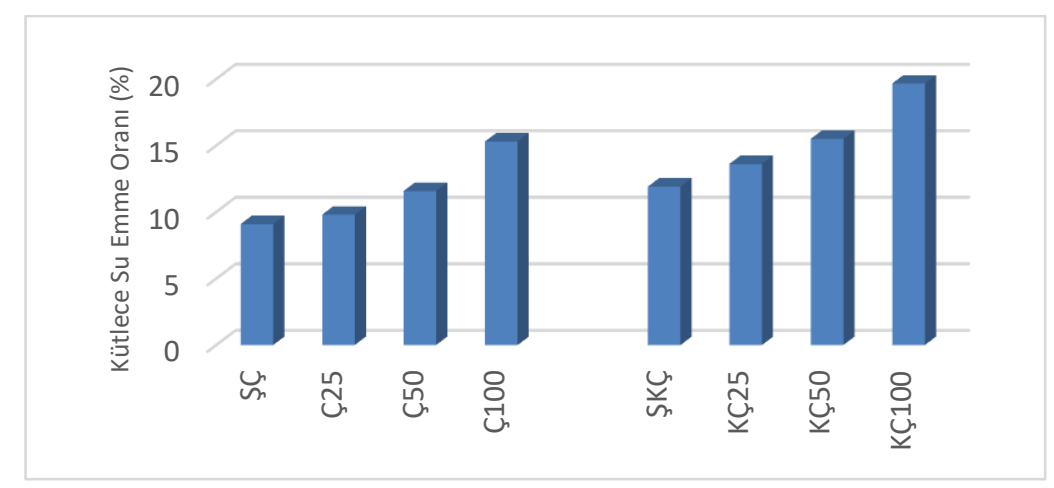

Şekil 5. Harç serilerine ait kütlece su emme değerleri

Ç grubu harçlarda kütlece su emme oranlarının \%9 ile \%15.5 arasında, KÇ grubu harçlarda ise \%12 ile \%20 arasında olduğu hesaplanmıştır. GCK'nın 1-4 mm arasında \%25 kullanımıyla referans serilerinden Ç grubunda \%7, KÇ grubunda ise \%13 daha fazla su emdiği tespit edilmiştir. GCK'nın \%100 oranında ikamesi ile ise bu oranlar Ç grubunda \%41, KÇ grubunda ise \%39 olarak hesaplanmıştır.

Her iki grupta GCK oranları eşit olan seriler karşılaştırıldığında; \%25 GCK içeren serilerde \%28, \%50 GCK içeren serilerde $\% 25$ ve $\% 100$ GCK içeren serilerde ise $\% 22$ oranında KÇ grubunun daha fazla suyu emdiği tespit edilmiştir.

\section{B. MEKANIK ÖZELLIKLER}

Harç serilerinin mekanik özelliklerin belirlenmesi için; tek eksenli yük altında basınç dayanımı deneyleri gerçekleştirilmiştir. Elde edilen sonuçlar Şekil 6'da gösterilmiştir.

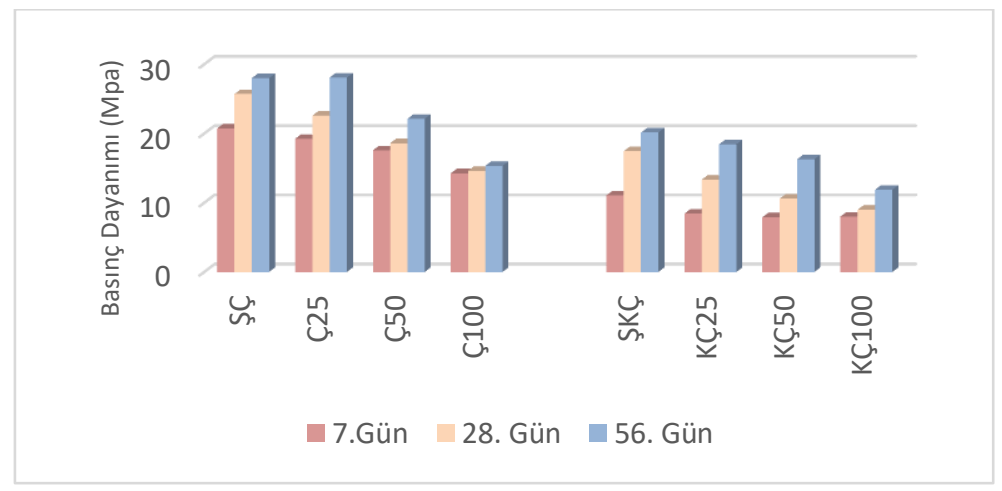

Şekil 6. Harç serilerine ait basınç dayanımı grafiği

Numunelere ait basınç dayanımı Şekil 6'da verilmiş olup, şekil incelendiğinde GCK miktarının artmasıyla beraber basınç dayanımı değerlerinin azaldığı görülmektedir. Bununla beraber harç numunelerinin basınç dayanımı kapasiteleri 7, 28 ve 56 gün aralı̆̆ında artan bir eğilim sergilemiştir. KÇ serilerinde Ç serilerine nazaran daha düşük basınç dayanımı değerleri elde edilmiştir. Basınç dayanımı verileri dikkate alındığında \%100 GCK kullanılan hem çimentolu hem de çimento ve kireç bağlayıcılı serilerin sonuçlarının birbirine yakın olduğu görülmüştür. Harç içerisinde yüksek miktarda GCK kullanımıyla basınç dayanımlarında bağlayıcı tipi farklılığının etkisinin az olduğu tespit edilmiştir. 


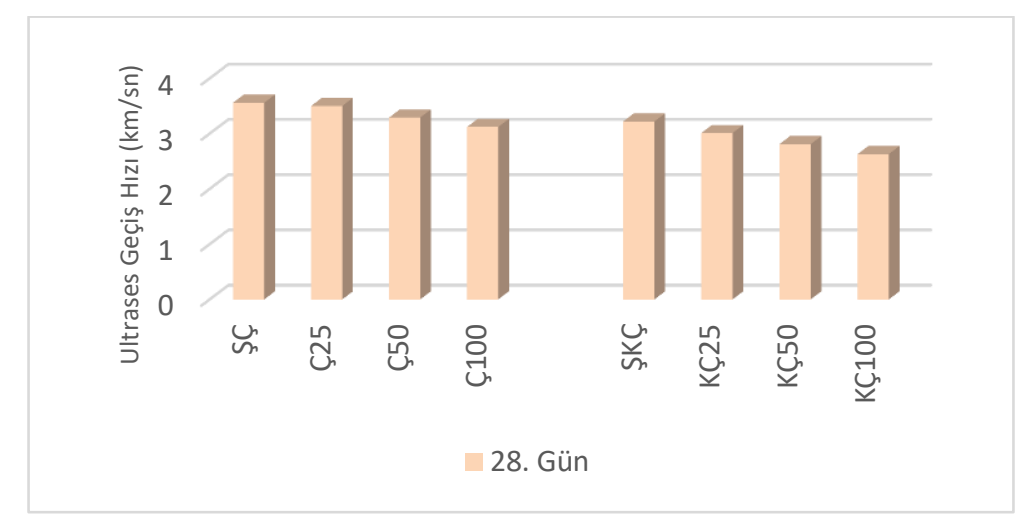

Şekil 7. Harç serilerine ait ultrases geçiş hızı grafiği

Şekil 7 incelendiğinde GCK miktarının artmasıyla beraber ultrases geçiş hızı değerlerinin azaldığı görülmektedir. Agrega yapısında ve dolayısıyla harçta artan boşluk miktarı ultrases hızının azalmasında önemli bir rol oynadığını söyleyebiliriz. Bununla birlikte çimentonun yanında bağlayıcı olarak kireç ilavesi ile birlikte ultrases geçiş hızı değerinde kireç olmayan harç karışımlarına nazaran azalma gözlemlenmiştir.

\section{SONUCLAR}

Genleştirilmiş cam küre (GCK) agregasının harç içerisinde farklı oranlarda kullanılmasıyla üretilen harç numuneleri üzerinde yapılan deneyler ile fiziksel ve mekanik özellikleri belirlenmiş ve elde edilen sonuçlar aşağıda özet olarak verilmiştir.

- Genleştirilmiş cam küre agregası, yüksek 1sıda oluşan gözenekli yapısı sayesinde normal agregalardan daha düşük birim ağırlığa sahiptir. Dolayısıyla harç içerisinde GCK kullanım oranı arttıkça, üretilen harçların birim ağırlıkları lineer olarak azalmaktadır.

- Tüm seriler incelendiğinde, harç içerisinde GCK kullanım oranıyla doğru orantılı olarak porozite ve kütlece su emme oranının artmış olduğu belirlenmiştir.

- Harç serilerinde GCK artışıyla basınç dayanımlarında azalma saptanmıştır. Basınç dayanımı verilerinde \%25 GCK kullanımının belirgin bir azalma göstermediği ancak GCK'nın \%50 ve \%100 oranlarında kullanımında dayanımların yaklaşık olarak \%45 oranında azaldığı tespit edilmiştir.

- Ayrıca GCK agregasının harç ve betonda farklı oran ve fraksiyonlarda kullanılmasıyla üretilen numunelerin fiziksel, termal ve mekanik özelliklerinin belirlenerek hafif yapı malzemelerine ait literatürün geliştirilmesi faydalı olacaktır.

TEȘEKKÜR: Deneysel çalışmada kullanılan genleştirilmiş cam küre agregasının Türkiye temsilcisi Omnis Kompozit Ltd. firmasına teşekkür ederiz. 


\section{KAYNAKLAR}

[1] H.Y. Ersoy, Kompozit Malzeme, Literatür Yayınevi, İstanbul, Türkiye: 2001, ss. 20-21.

[2] A.E. Fiorato, "Inspection guide for reinforced concrete vessels," Portland Cement Association, Illinois, No. CG-M-11-81, 1981.

[3] İ.B. Topcu, "Semi-Lightweight concretes produced by volcanic slags," Cement And Concrete Research, vol. 27, no. 1, pp. 15-21, 1997.

[4] H. Al-Khaiat, M.N. Haque, "Effect of initial curing on early strength and physical properties of lightweight concrete," Cement and Concrete Research, vol. 28, no. 6, pp. 859-866, 1998.

[5] E. Yasar, C.D. Atis, A. Kilic and H. Gulsen, "Strength properties of lightweight concrete made with basaltic pumice and fly ash,” Materials Letters, vol. 57, pp. 2267-2270, 2003.

[6] S. Gökçe, Ö. Can, "Pomza agregasının farklı zamanlardaki su emmelerinin hafif betonun mekanik ve fiziksel özelliklerine etkisi," Gazi Üniversitesi Politeknik Dergisi, cilt. 12, sayı. 4, ss. 293298, 2009.

[7] Elrahman, M.A., Chung, S.Y. and Stephan, D., "Effect of different expanded aggregates on the properties of lightweight concrete," Magazine of Concrete Research, vol. 71, no. 2, pp. 95-107, 2019.

[8] S. Subaşı, A. Beycioğlu ve M. Emiroğlu, "Genleştirilmiş kil agregalı hafif betonlarda bulanık mantık yöntemiyle yarmada çekme dayanımı tahmin modeli geliştirilmesi," Osmangazi Üniversitesi Mühendislik-Mimarlık Fakültesi Dergisi, cilt. 22, sayı. 3, ss. 157-166, 2009.

[9] S. B. Fındık, "Yüksek sıcaklık etkisinde kalan mineral katkılı ve genleştirilmiş perlit agregalı harçların bazı özellikleri," Y. Lisans Tezi, İnşaat Mühendisliği Bölümü, Atatürk Üniversitesi, Erzurum, Türkiye, 2007.

[10] M. Aytekin, "Sepiyolit içeren çimento esaslı bağlayıcılarla üretilen harçların işlenebilirlik, dayanım ve dayanıklılık özelliklerinin araştırılması,” Y. Lisans Tezi, İnşaat Mühendisliği Bölümü, Kilis 7 Aralık Üniversitesi Kilis, Türkiye, 2018.

[11] J. Gadea, A. Rodríguez, P.L. Campos, J. Garabito and V. Calderón, "Lightweight mortar made with recycled polyurethane foam, Cement and Concrete Composites, vol. 32, no. 9, pp. 672-677, 2010.

[12] Stikloporas, (2019). Technical data sheet [Online]. Available: https://stikloporas.com/wp content/uploads/2019/12/tds_stikloporas_en.pdf

[13] E. Namsone, G. Sahmenko, A. Korjakins, and E. Namsone, "Influence of porous aggregate on the properties of foamed concrete," Construction Science, vol. 19, pp. 13-20, 2016. 